\title{
Minimum Quantity Lubrication (MQL) and its Effect on Tool Wear During Miniature Drilling: An Experimental Study
}

\author{
Norsalawani Mohamad, and Rubina Bahar

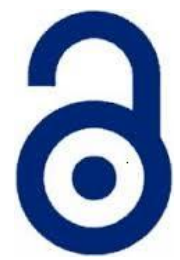 \\ Received: 06 October 2016 \\ Accepted: 13 December 2016 \\ Published: 20 December 2016 \\ Publisher: Deer Hill Publications \\ (c) 2016 The Author(s) \\ Creative Commons: CC BY 4.0
}

\begin{abstract}
Miniature drilling is widely used in industries including electronics and reconstructive surgeries to create small sized holes. Chip removal and effective supply of coolant are the two limiting factors that make the process more complex compared to other meso scale machining processes and also contribute to the tool wear. The tool wear in the process is mainly caused by the interaction, motion and chip production between the tool and work piece. Uniform supply of coolant must be ensured to reach the drilled cavity to keep the tool wear to a minimal level. This study includes experimental investigation of the tool condition after applying Minimum Quantity Lubrication (MQL) system as a greener approach as the name indicates. The tool condition with MQL has also been compared with dry and flood cooling. Two different types of drill bit materials (High Speed Steel and Carbide) have been tested under same experimental condition to drill through Aluminum Alloy 6061 and it has been found that overall performance in terms of tool condition after applying MQL was better compared to the other two methods. The overall wear propagation area was measured for both the conditions. It was seen, the wear propagation covered minimal area with MQL while for flood and dry condition wear was spread over a bigger area on flank.
\end{abstract}

Keywords: Minimum Quantity Lubrication (MQL), Micro-drilling, HSS drill bit, Carbide drill bit, Tool wear.

\section{INTRODUCTION}

In all metal cutting operations, one of the most significant limitation is tool wear. It is caused by the normal load generated by the interaction, motion and chips produced between tool and work piece. It is important to improve the tool life, minimizing the tool wear and improve the performance of machining operations. During machining, cutting fluids also play an important role to provide necessary cooling and lubrication to protect from corrosion with enhanced chip flushing. The machined surface as well as the cutting tool's condition is significantly affected by the cutting fluid. Among the different types of lubrication system, the major two categories are flooding and mist application[1]. Minimum Quantity Lubrication (MQL) system falls under the latter category. MQL uses a very small amount of a fluid. According to the German DIN specification, up to $50 \mathrm{~mL} /$ hour of lubricant (for some exceptional cases up to $150 \mathrm{~mL} / \mathrm{hour}$ ) can be classified under MQL [2]. Although the amount may vary greatly depending on the materials, processes and the tools as some materials are naturally more lubricant than others, some processes are better able to get the fluid to the right place, and bigger tools need more lubricant than smaller ones [3]. MQL has been proven to be effective in terms of tool wear for various machining like grinding $[4,5]$, milling $[6,7]$ turning $[8$, 9] and many more. MQL has larger scope to be applied in mini to micromachining as well due to the requirement of less heat removal rate and effective chip removal [3]. For micro-drilling, effect of MQL is more significant as the mist coolant is more capable of entering the micro channel between the drill bit and the newly created hole; as small scale drilling is susceptible to clogging of chips with the tool [10]. For overall drilling purposes, MQL has been able to draw significant attention in terms of lower rate of Built Up Edge (BUE) formation and tool life compared to dry condition[11], drilled hole roundness deviation was better using MQL compared to dry and flood coolant as reported

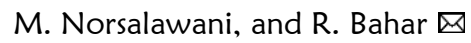 \\ Department of Manufacturing and Materials Engineering \\ International Islamic University Malaysia \\ PO Box 10, 50728 Kuala Lumpur, Malaysia \\ E-mail: rbahar@iium.edu.my
}

Reference: Norsalawani, M., and Bahar, R. (2016). Minimum Quantity Lubrication (MQL) and its Effect on Tool Wear During Miniature Drilling: An Experimental Study. International Journal of Engineering Materials and Manufacture, 1(2), 65-70 
by [12]. In terms of different coatings of the cemented carbide drill as reported by [13], with a special design of the drill to have better mist distribution, the performance was equivalent to flood cooling.

In this paper, two different material drill bits have been tested for the tool wear condition under three lubrication condition: flood, MQL and dry for drilling on Aluminum alloy 6061. MQL is found to be a better choice for both the tools. The average area of the wear was measured and compared for the tools used under different condition.

\section{METHODOLOCY}

\subsection{Equipment and Material Selection}

The micro drilling machine used to conduct the experiment is Mikrotools Multi-Process Machine Tool DT110. This machine can travel in three directions which are $\mathrm{X}, \mathrm{Y}$ and $\mathrm{Z}$ axis. For this project, the Aluminium alloy 6061 has been chosen for the work piece material with medium fatigue strength and good finishing characteristic. Two drill bits of HSS and Carbide with $1 \mathrm{~mm}$ diameter, same drill point angle and cutting direction were used.

\subsection{Minimum Quantity Lubrication System and other equipment}

Bluebe MQL system was used with an environment friendly biodegradable lubricant. It also served as the necessary coolant. Bluebe FK type can deliver air and lubricant to the nozzles which can be adjusted separately with lubricant consumption 4-8 ml per hour / per nozzle. Accu-Lube LB-6000 was used as the lubricant with vegetable oil base. Nikon Measuring Microscope model MM-400/L is used to measure the wear obtained on the tool. The microscope is connected to the computer to capture the image of cutting tool by using NIS-Element F3.0 software. Design of experiment $(D O E)$ is required to determine the relationship between the variables and parameters that will affect the response and performance. For this study, two level factorial design was used by using Design-Expert 6.0.8 software.

\subsection{Experimental Parameters}

This study investigates the performance of MQL over other two methods of lubrication dry lubrication and flood lubrication. Figure 2(a-b) shows flood condition and MQL condition respectively. The Experimental parameters are listed in Error! Reference source not found..

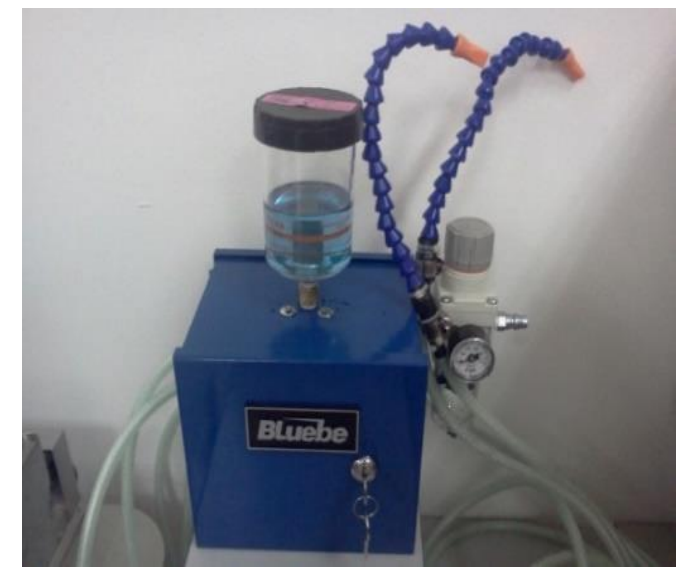

Figure 1: The BLUBE MQL system

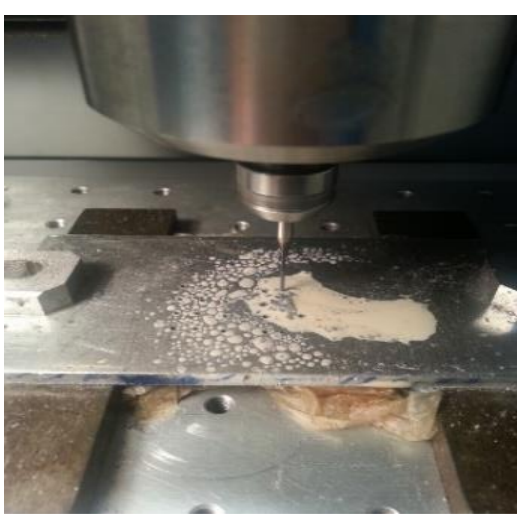

(a)

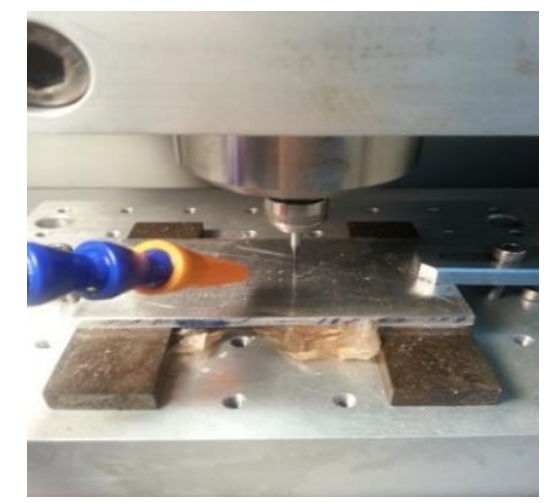

(b)

Figure 2: Drilling with (a) flood coolant (b) MQL 
Table 1: Experimental Parameters

\begin{tabular}{ll}
\hline Parameter & Description \\
\hline Work piece Material & Aluminum Alloy 6061 \\
Cutting tool diameter & $1.00 \mathrm{~mm}$ \\
Depth of cut & $6 \mathrm{~mm}$ \\
Feed rate $(\mathrm{mm} / \mathrm{min})$ & 8.0 \\
Spindle speed $(\mathrm{rpm})$ & 25000 \\
Tool material & Carbide and high speed steel \\
Lubrication condition & Dry/Flood/MQL \\
& \\
\hline
\end{tabular}

Table 2: Types of wear found on the tools

\begin{tabular}{|c|c|c|c|c|}
\hline Tool & Lubrication Method & Tool Wear Observa & & \\
\hline 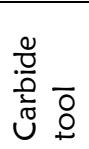 & $\begin{array}{l}\text { Dry } \\
\text { Flood } \\
\text { MQL }\end{array}$ & $\begin{array}{l}\text { Flank wear } \\
\text { Plastic deformation } \\
\text { Crater wear }\end{array}$ & $\begin{array}{l}\text { Crater wear } \\
\text { Flank wear } \\
\text { Flank wear }\end{array}$ & $\begin{array}{l}\text { Adhesion } \\
\text { Crater wear }\end{array}$ \\
\hline $\begin{array}{l}\overline{0} \\
\stackrel{0}{ \pm} \\
\tilde{I}\end{array}$ & $\begin{array}{l}\text { Dry } \\
\text { Flood } \\
\text { MQL }\end{array}$ & $\begin{array}{l}\text { Flank wear } \\
\text { Crater wear } \\
\text { Flank wear }\end{array}$ & $\begin{array}{l}\text { Crater wear } \\
\text { Flank wear } \\
\text { Adhesion }\end{array}$ & $\begin{array}{l}\text { Burr } \\
\text { Crater wear }\end{array}$ \\
\hline
\end{tabular}

\section{RESULTS}

\subsection{The Tool Wear Analysis}

The tool wear has been analysed to compare the effect of different lubrication processes on tool wear of different materials drill bits. Initial experiment was conducted on carbide drill bit under dry machining conditions with feed rate of $4 \mathrm{~mm} / \mathrm{min}$ and spindle speed of $18000 \mathrm{rpm}$. However, no significant wear was seen on the tool bit. The feed rate and spindle speed are increased to the $8 \mathrm{~mm} / \mathrm{min}$ and $25000 \mathrm{rpm}$ respectively to obtain clear and significant tool wear. Then all the experiments conditions are conducted with those new cutting parameters. The types of wear observed for two different drill bit is listed in Table 2.

\subsection{Observation of tool wear between the processes and tool material}

The results of the experiments were compared for the tool wears occurred during dry machining, presence of flood coolant and with MQL for every tool bit. The observations of tool wear is done using Nikon Measuring Microscope. Total area of wear is measured and compared for each condition. Mainly crater wear and flank wear were observed on the tool with presence of adhesion and burr in some cases. Crater wear usually results from the high temperature at the contact zone, or it exceeds the level of resistivity of the cutting materials. It is formed as a concave section on the tool face formed by the sliding action of chips on the surface while flank wear mainly occurs due to high cutting speed, low percentage of oil in fluid flow and insufficient cutting fluid. It occurs on the tool flank as a result of friction between the machined surface of the work piece and the tool flank.

The most significant observations that can be seen is the adhesion of work material to the drill bit. When machining the aluminum work piece under the combined action of the temperature and pressure, the chip adhesion with the cutting tools took place. A patch of wear including circular grooves has grown significantly in flood coolant for both materials, and among them, the carbide tool bit has more adhesion because it has the least abrasive resistance. Error! Reference source not found. summarizes the crater wear and Error! Reference source not found. describes the flank wear observed for the two tools under the three different lubrication conditions. From these tables, it can be seen that flank wear was more obvious on dry machining. It occurred because the high temperature and friction at the tool-work piece area. 
Table 3: Crater wear for Carbide and HSS tools

\begin{tabular}{|c|c|c|c|}
\hline Experiment conditions $\rightarrow$ & Dry machining & Flood coolant & MQL \\
\hline Carbide Tool & & & \\
\hline HSS Tool & & & \\
\hline
\end{tabular}

Table 4: Flank wear for Carbide and HSS tools

\begin{tabular}{llll}
\hline Experiment conditions $\rightarrow$ Dry machining & Flood coolant \\
Carbide Tool & &
\end{tabular}

The flute of high speed steel and carbide tool bits were also compared as seen in Error! Reference source not found.. The HSS tool had more obvious tool wear, compared to carbide. This may be attributed to carbide's inherent higher hardness and toughness which enabled the carbide tool to maintain high hardness at elevated temperature, and therefore, absorbing more energy before fracture. Error! Reference source not found. summarizes the overall wear propagation area considering crater and flank wear. As it can be seen from the table that the propagation of wear over the tool surface was minimum with applying MQL for both the tools. The effect of MQL was more dominant for HSS tool for flank wear and for crater wear, MQL provided better machining condition for the carbide tool.

Figure 3 shows the interaction graph extracted from Design Expert plot. The comparison between flood and MQL has been presented here as the dry and flood condition results were quite close. It is observed from the figures that crater wear affected Carbide tool more significantly compared to HSS tool. MQL has proven to be the best possible lubrication option among the available three methods. When considering flank wear, Carbide tool was stronger 
compared to HSS tool. In terms of lubrication method, still MQL is proven to be the one to provide better tool quality irrespective of tool material used.

Table 5: Flute condition for Carbide and HSS tools

\begin{tabular}{llll}
\hline Experiment conditions & Dry machining & Flood coolant \\
Carbide Tool & & MQL \\
HSS Tool &
\end{tabular}

Table 4: Results comparison of crater wear and flank wear

\begin{tabular}{ccccc}
\hline Run & Tool Materials & Machining conditions & Crater Wear Area $\left(\mathrm{mm}^{2}\right)$ & Flank Wear Area $\left(\mathrm{mm}^{2}\right)$ \\
\hline 1 & HSS & Flood Coolant & 0.0925 & 0.0995 \\
2 & HSS & MQL & 0.088 & 0.0483 \\
3 & HSS & Dry & 0.131 & 0.0657 \\
4 & Carbide & Flood Coolant & 0.127 & 0.0295 \\
5 & Carbide & MQL & 0.0967 & 0.0198 \\
6 & Carbide & Dry & 0.2495 & 0.1079
\end{tabular}

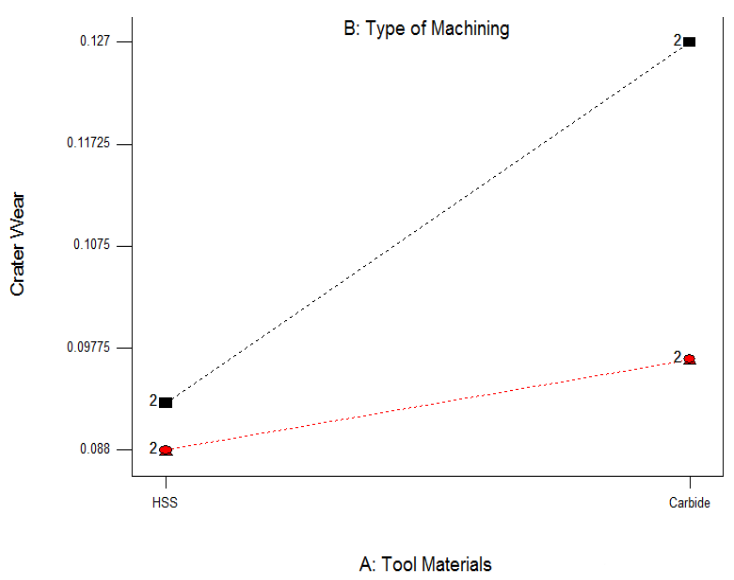

(a)

- B1 Flood Coolan

$\triangle \mathrm{B} 2 \mathrm{MOL}$

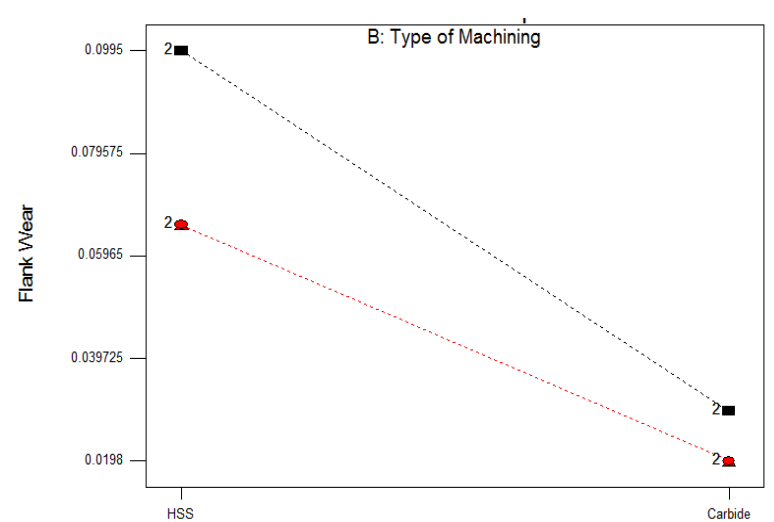

(b)

- B1 Flood Coolan
B2 MOL 
Figure 3: Interaction graph between experiment conditions and tool materials on the tool wear $[X=A$ : Tool Material, $\mathrm{Y}=\mathrm{B}$ : Type of Coolant

\section{CONCLUSIONS}

An experimental study was conducted to observe the tool condition using three different method of lubrication: Dry, Flood and MQL for drilling miniature holes in Aluminium 6061 alloy. Two different material drill bits (HSS and Carbide) with same geometric parameters have been used. It has been observed after machining that MQL provided better tool condition in terms of flank wear, crater wear and flute condition. The wear propagation was minimal when using MQL method. It is evident from the results that MQL mist had better cooling effect as it could enter the cavity between the drill bit and drilled hole easily due to lower surface tension during machining compared to flood coolant. However, the tools behaved differently for different types of wear. The findings can be summarized as:

- MQL is suitable for different type of tool material for miniature drilling.

- The tool wear propagation is minimum when using MQL compared to dry and flood coolant condition.

- Different material tool behaved differently in terms of crater and flank wear; HSS was found to be strong when crater wear was investigated while Carbide tool had least flank wear under MQL and flood condition.

\section{ACKNOWLEDGEMENTS}

The Authors are grateful to the Kulliyyah of Engineering, International Islamic University Malaysia for necessary technical and financial support for the work.

\section{REFERENCES}

1. Groover, M. P. (2013). Fundamentals of Modern Manufacturing.

2. Standards (2011) committee tools and clamping devices (FWS) working committee, DIN 69090-1 MQL Maching Technology - Part 1. Terms and Definitions.

3. Walker, T. (2013). The Handbook: A guide to machining with minimum quantity lubrication, V 1.0.3. Unist, Inc.

4. Hadad, M. J., Tawakoli, T., Sadeghi, M. H., \& Sadeghi, B. (2012). Temperature and energy partition in minimum quantity lubrication-MQL grinding process. International Journal of Machine Tools and Manufacture, 54-55, 1017.

5. Da Silva, L. R., Bianchi, E. C., Fusse, R. Y., Catai, R. E., Franca,T. V., \& Aguiar, P. R. (2007). Analysis of surface integrity for minimum quantity lubricant-MQL in grinding. International Journal of Machine Tools and Manufacture, 47(2), 412-418.

6. Rahman, M., Senthil Kumar, A., \& Salam, M. U. (2002). Experimental evaluation on the effect of minimal quantities of lubricant in milling. International Journal of Machine Tools and Manufacture, 42(5), 539-547.

7. Iqbal, A., Al-Ghamdi, K. A., \& Hussain, G. (2016). Effects of tool life criterion on sustainability of milling. Journal of Cleaner Production, 139, 1105-117.

8. Attanasio, A., Gelfi, M., Giardini, C., \& Remino, C. (2006). Minimal quantity lubrication in turning: Effect on tool wear. Wear, 260(3), 333-338.

9. Hadad, M. \& Sadeghi, B. (2013). Minimum quantity lubrication-MQL turning of AISI 4140 steel alloy. Journal of Cleaner Production, 54, 332-343.

10. Smith, G. T. (2008). Cutting tool technology: industrial handbook. Springer.

11. Bhowmick, S., Lukitsch, M. J., \& Alpas, A. T. (2010). Dry and minimum quantity lubrication drilling of cast magnesium alloy (AM60). International Journal of Machine Tools and Manufacture, 50(5), 444-457.

12. Ahsan, N. M. M., Kibria, G. M., Ahmed, R. M., Islam, A. M., \& Hossain, M. M. (2010). Performance evaluation of minimum quantity lubrication (MQL) in drilling operation," in International Conference on Mechanical, Industrial and Energy Engineering, 1-5.

13. Fox-Rabinovich, G., Dasch, J. M., Wagg, T., Yamamoto, K., Veldhuis, S., Dosbaeva, G. K., \& Tauhiduzzaman, M. (2011). Cutting performance of different coatings during minimum quantity lubrication drilling of aluminum silicon B319 cast alloy. Surface and Coatings Technology, 205(16) 4107-4116. 